\title{
Long-Term Evaluation of the Influence of Mechanical Pruning on Olive Growing
}

(1)

\author{
A. B. Dias,*J. O. Peça, and A. Pinheiro
}

\begin{abstract}
In Portugal, olive (Olea europaea L.) traditional groves of around 100 trees ha $^{-1}$ necessitate increasing pruning costs every year. As a result farmers tend to lengthen pruning intervals. With the purpose of studying an alternative to the expensive, labor-intensive manual pruning practice, field trials were established with three treatments: (i) manual pruning with a chain saw; (ii) mechanical pruning, performed by a tractor mounted circular disc-saws cutting bar; and (iii) mechanical pruning, as in the mechanical pruning treatment, followed by a manual pruning complement. Olive production and harvesting efficiency were evaluated every year for $8 \mathrm{yr}$. Olives were harvested with a trunk shaker, and the remaining nondetached fruits were collected manually. The pruning rate of mechanical pruning $\left(487\right.$ trees $\left.^{-1} \mathrm{man}^{-1}\right)$ was substantially higher than the values of manual pruning and mechanical+manual pruning, which were the same $\left(20\right.$ trees $\left.\mathrm{h}^{-1} \mathrm{man}^{-1}\right)$. Over the 8 -yr period, mechanical pruning had an average yield of $36.4 \mathrm{~kg}$ tree $^{-1} \mathrm{yr}^{-1}$ which was significantly higher than the $30.1 \mathrm{~kg}$ tree $^{-1} \mathrm{yr}^{-1}$ of manual pruning and no significantly different from the $34.1 \mathrm{~kg} \mathrm{tree}^{-1} \mathrm{yr}^{-1}$ of mechanical+manual pruning. The shaker efficiency was significantly influenced by the year, ranging from 72 to $96 \%$; no significant differences were found between treatments in terms of harvesting efficiency. Results indicate that after mechanical pruning trees can be kept for at least $8 \mathrm{yr}$ without any significant loss in olive yield and no effect in harvesting efficiency, therefore reducing costs. Mechanical+manual pruning, performed in the same year, did not yield further improvement.
\end{abstract}

$I^{1}$

T IS A FACT that farmers face increasing costs on labor-intensive manual pruning of olive trees. Pruning intervals tend to be lengthened and trees are left severely pruned when finally the operation is performed. It is expected that such substantial reduction in the volume of the canopy may lead to a decrease in production, at least in following years until the tree has recovered. Although no precise data was found available to quantify the overall problem, it is believed that a cheaper, more mechanized, less labor-intensive technique is needed. These facts justify this study.

A mechanized alternative involves pruning cuts made in the tree canopy by a tractor-mounted cutting device progressing at a constant speed between the tree rows (Pastor and Humanes, 1998). The potential of mechanized vs. manual pruning was previously shown in long-term research by these authors. They conducted rain-fed field trials in a 12 by $12 \mathrm{~m}$ olive grove array using the Picual cultivar. Observations from 1981 to 1997 revealed similar olive yield per tree in mechanized and manual pruned trees. These authors also stated the importance of occasional manual selective pruning to clear excessive wood from trees that were subjected to mechanized pruning.

Pastor and Humanes (1998) also conducted rain-fed field trials in a much denser olive grove of 8 by $4 \mathrm{~m}$ using the same cultivar.

Departamento de Engenharia Rural da Universidade de Évora/Instituto de Ciências Agrárias e Ambientais Mediterrânicas, Núcleo da Mitra, Apartado 94, 7002-554 Évora, Portugal. Received 6 May 2011. *Corresponding author (adias@uevora.pt).

Published in Agron. J. 104:22-25 (2012)

Posted online 7 Nov 2011

doi:10.2134/agronj2011.0137

Available freely online through the author-supported open access option.

Copyright (c) 2012 by the American Society of Agronomy, 5585 Guilford Road, Madison, WI 53711. All rights reserved. No part of this periodical may be reproduced or transmitted in any form or by any means, electronic or mechanical, including photocopying, recording, or any information storage and retrieval system, without permission in writing from the publisher.
The objective was to compare different intervals for mechanized pruning with traditional manual pruning. Observations from 1981 to 1989 revealed that in all the mechanized pruning tests, irrespective of pruning interval, olive yield per tree was similar to the yield of manual pruned trees. These tests indicate that mechanized pruning does not need to occur at frequent intervals, thus it can be part of a management program that reduces costs.

Pastor and Humanes (1998) also conducted field trials of different pruning methods executed every $2 \mathrm{yr}$, methods included selective manual pruning, mechanical pruning, and mechanical pruning complemented by a manual clearing of excessive wood. Observations from 1989 to 1997 revealed that all the mechanized pruning treatments with or without manual complement, resulted in similar olive yield per tree which, in turn, was significantly higher than the yield of manual pruned trees. This research emphasized the potential of mechanized pruning as well as suggesting that a selective manual complement to the mechanized pruning does not provide any further advantages. Fontanazza and Baldoni (1991) and Fontanazza (1996) put forward sequences of pruning action combining mechanized pruning and manual pruning to be performed in different years.

The potential of the sequence suggested by Fontanazza (1996) was evaluated by Camerini et al. (1999). Field trials were conducted in a rectangular array of 6 by $3 \mathrm{~m}, 8$ yr-old olive grove of the Frantoio and Leccino cultivars, trained as "monocone". The sequence started by hedging both sides of the tree in the first year, no cut in the second year, followed by manual pruning in the third year to clear excessive wood. Observations over a period of $9 \mathrm{yr}$ revealed that trees subjected to the purposed pruning sequence showed an average $59 \%$ increase in olive yield relative to trees strictly manual pruned. Fontanazza (1996) and Giametta and Zimbalatti (1994) reported an important increase on rate of pruning using mechanized techniques even if a manual pruning complement is required. Other researchers (Pastor,1982; 